Hispania Sacra, LXII

126, julio-diciembre 2010, 539-562, ISSN: 0018-215-X

\title{
LA HEREJIZACIÓN DE LA SODOMÍA EN LA SOCIEDAD MODERNA. CONSIDERACIONES TEOLÓGICAS Y PRAXIS INQUISITORIAL
}

\author{
POR \\ FERNANDA MOLINA \\ Instituto de Historia Argentina y Americana «Dr. Emilio Ravignani», Buenos Aires
}

\section{RESUMEN}

En su incansable tarea por defender la ortodoxia religiosa, la Inquisición persiguió y castigo cualquier forma de herejía. Sin embargo, tanto el Santo Ofício aragonés como los tribunales dependientes de su secretaría contaron con una competencia adicional: perseguir los delitos vinculados con el llamado «pecado nefando». Más allá de las contingencias históricas que llevaron a esta situación, este trabajo se propone abordar las condiciones teológicas que posibilitaron la persecución de la sodomía y su progresiva vinculación con la herejía.

PALABRAS CLAVE: Sodomía, herejía, sexualidad, teología, inquisición.

\section{THE «HERESYSATION» OF SODOMY IN MODERN SOCIETY. THEOLOGICAL CONSIDERATIONS AND PRAXIS INQUISITORIAL}

\begin{abstract}
In order to defend religious orthodoxy, the Inquisition relentlessly pursued and punished any kind of heresy. However, Aragonese courts had an additional jurisdiction for the prosecution of all the crimes related to the so-called «abominable sin». This paper aims to analyze the theological conditions which led to the persecution of sodomy as well as its progressive relationship with heresy.
\end{abstract}

KEY WORDS: Sodomy, heresy, sexuality, theology, inquisition.

Recibido/Received 17-06-2008

Aceptado/Accepted 14-10-2009 
Este trabajo se propone indagar en torno a la relación entre la práctica de la sodomía y la noción de herejía. La preocupación por este tema radica en el hecho de que tanto la Inquisición aragonesa como algunos de los tribunales dependientes de su secretariado gozaron de la prerrogativa de intervenir judicialmente en la represión del llamado «pecado nefando». Si bien esta competencia fue el resultado de un breve papal emitido el 24 de febrero de 1524, existieron una serie de convergencias teológicas que, más allá de tratarse de dos fenómenos diferentes, favorecieron el reconocimiento inquisitorial de la sodomía como un comportamiento con contenido herético.

Entre los antecedentes de esta investigación, puede mencionarse una serie de trabajos asociados con el estudio del Santo Oficio aragonés, dado que una de las fuentes por excelencia para abordar el problema de la sodomía moderna procede de las causas incoadas por este tribunal. ${ }^{1}$ En términos generales, pueden reconocerse dos grandes líneas de investigación: en primer lugar, una serie de estudios que, partiendo del estudio de la institución inquisitorial, abordó la sodomía como uno de los tantos delitos perseguidos por sus tribunales y, en segundo lugar, otro grupo de investigaciones que, centrado en el análisis específico de la sodomía, recurrió al estudio de la Inquisición como marco general en el que se insertaba su represión. Si bien el problema de la herejía esta presente en ambas líneas de trabajo, el abordaje ha sido superficial o indirecto, aún cuando era esta noción la que teóricamente habilitaba el conocimiento del tribunal inquisitorial en la persecución de los delitos.2

Con excepción de Stephen Haliczer, para quien la sodomía no constituía una herejía, salvo que tuviera lugar en contextos heréticos explícitos -como las juntas brujeriles o la lucha contra musulmanes y judíos- la mayoría de los autores

\footnotetext{
${ }^{1}$ Los tribunales inquisitoriales aragoneses fueron muy activos en la persecución del denominado «pecando nefando». Por ejemplo, entre 1540 y 1700 los tribunales de Zaragoza procesaron a 791 individuos acusados por sodomía, mientras que los de Valencia, aunque más moderados, intervinieron en 379 casos. Miguel Angel Motis DoLADER, «Imago Dei Deturpatur: El pecado «nefando» o «contra natura» en el Arzobispado de Zaragoza», Hispania Sacra 52/105, (2000) 355 y Miguel Angel CARRASCO, Inquisición y represión sexual en Valencia. Historia de los sodomitas (1565-1785), Barcelona, 1986, 69 .

${ }^{2}$ Dentro del primer tipo de investigación pueden identificarse los trabajos de Rafael CARRASCO: Inquisición y represión... y «Herejía y Sexualidad en el Siglo de Oro», Los cuadernos del Norte, 6 (34) (1985) 62-72; William MonTER, «La Sodomie à l'époque moderne en Suisse romande», Annales, 29 (1974) 1023-1033; André FERNÁNDEZ, «The Repression of Sexual Behavior by the Aragonese Inquisition between 1560 and 1700», Journal of the History of Sexuality, 7, 4 (1997) 469-501; Cristian BERCO, Sexual Hierarchies, Public Status. Men, Sodomy, and Society in Sapain's Golden Age, Toronto, 2007. Respecto de la segunda línea de investigación pueden citarse las obras de Bartolomé BENNASSAR, Inquisición española: poder político y control social, Barcelona, 1984 (1981), 195-320, Stephen HalicZER, Inquisition and Society in the Kingdom of Valencia, 1478-1834, California, 1990 y Ricardo GARCía CÁrCel, y Doris Moreno Martínez, Inquisición. Historia Crítica, Barcelona, 2000.
}

Hispania Sacra, LXII

126, julio-diciembre 2010, 539-562, ISSN: 0018-215-X 
observan algún tipo de vinculación entre ambos fenómenos. ${ }^{3}$ Por ejemplo, para García Cárcel y Bartolomé Bennassar, los inquisidores consideraban a la sodomía como un tipo de herejía, en la medida en que se trataba de un pecado de sensualidad y de razón y, como tal, un comportamiento herético. ${ }^{4}$ No obstante, el resto de las investigaciones sobre el tema son más cautas a la hora de trazar una identificación directa. En esa línea, Rafael Carrasco observa un sutil acercamiento entre ambos pecados, aun cuando ni los inquisidores ni los teólogos los definieran en los mismos términos. Según el autor, la sodomía entraba en una zona de peligrosidad ambigua que, en tanto representaba un atentado contra Dios, podía considerarse una suerte de cuasi herejía. Para André Fernández, también existe una tenue relación entre ambos pecados, cuyo fundamento debe buscarse en el contenido sexual de la sodomía que, en este sentido, podía llegar a interpretarse como un error de fe. Asimismo, el conocimiento inquisitorial de la sodomía debe entenderse en el contexto de expansión jurisdiccional de la institución hacia el campo de la moralidad, hasta entonces fuera de su alcance. ${ }^{5}$ Por su parte, William Monter observa un progresivo acercamiento entre ambos fenómenos durante los siglos XII y XV. Para el autor, las autoridades eclesiásticas que comenzaron a preocuparse por los grupos neo-maniqueos, interpretaron la aversión por las relaciones heterosexuales como prueba de sodomía. Estas acusaciones florecieron durante la persecución de la herejía cátara en los siglos XII y XIII y durante la represión a los templarios. Al constituir un delito de fuero mixto, la justicia laica incorporó esa identificación entre sodomía y herejía, empezando a considerar a muchos herejes como sodomitas y a admitir que los sodomitas eran, ipso facto, herejes. ${ }^{6}$ Finalmente, Cristian Berco observa que aún cuando las sodomía no constituía una herejía en un sentido clásico, el hecho que el estado -corporizado en las leyes reales o locales- se identificara a si mismo como cristiano y protector de la cristiandad, permitía su confluencia, después de todo ambos pecados representaban crímenes horrendo de traición a

\footnotetext{
${ }^{3}$ Para Haliczer, los procedimientos inquisitoriales desmienten cualquier tipo de vínculos con la herejía, ya que mientras los casos concernientes a acusaciones heréticas se revestían de un halo de ocultación, los de sodomía seguían el curso del procedimiento judicial ordinario, es decir, los testigos eran públicos, existía la práctica del careo, etc. Según el autor, la actuación de los tribunales inquisitoriales sobre el delito debe entenderse en el contexto de Post-Tridentino asociado con la defensa del matrimonio y la moral sexual católica. Stephen Haliczer, Inquisition and Society... 303. Henry Kamen también tiene una interpretación similar acerca del conocimiento del delito de sodomía por parte del Santo Oficio. Para el autor, además de seguir la tradición de la Inquisición medieval, la jurisdicción inquisitorial sobre el delito estuvo vinculada con las necesidades de la Contrarreforma por purificar las costumbres sexuales de los españoles. Henry KAMEN, «Notas sobre brujería y sexualidad y la Inquisición», Inquisición española y mentalidad inquisitorial, Ángel Alcalá et al., 226-236, Barcelona, 1984, 334.

${ }^{4}$ Bartolomé BenNASSAR, Inquisición española... 296.

5 André FERnÁNDEZ, The Repression... 472.

6 William MonTER, La Sodomie... 1024.
} 
la comunidad cristiana y al Todopoderoso. ${ }^{7}$ Por otra parte, a pesar de la lucha jurisdiccional entre los diferentes fueros en los que caía el conocimiento de la sodomía, existió una cooperación entre las justicias seculares, eclesiásticas e inquisitoriales que reforzó la identificación de la sodomía con la herejía.

Si bien los autores citados reconocen la existencia de relaciones, más o menos directas, entre ambos fenómenos, ninguno de ellos aborda sistemáticamente los fundamentos teológicos que pudieron contribuir a su acercamiento, más allá de formulaciones generales sobre el tema. En este sentido, las siguientes secciones se abocan a reconstruir, desde la perspectiva del pensamiento erudito, el proceso de herejización de la sodomía. Para dicho fin, en primer lugar, se presenta el contexto político y jurídico que posibilitó que tanto la Inquisición aragonesa como los tribunales anexos intervinieran en los casos de sodomía; en segundo lugar, se aborda una serie de condiciones teológicas que posibilitaron la identificación entre el fenómeno de la sodomía con el de la herejía y, finalmente, se indaga en las actitudes y los comportamientos que los magistrados inquisitoriales y los reos tuvieron frente a la sodomía. Para ello, se analizan las cartas y las relaciones de causas de fe procedentes del Santo Oficio peruano que, a pesar de ser sufragáneo de la Secretaría de Aragón, tuvo una actitud ambigua y contradictoria respecto del delito de sodomía.

\section{Del DeCreto de la SupRema AL BREVE PAPAL}

En sentido estricto, el objetivo de la inquisición consistía en enmendar los errores doctrinales vinculados a la herejía. ¿Pero qué se definía por herejía? Según el teólogo y filósofo Robert Grosseteste (c.1230), la herejía se definía como una «proposición libremente elegida por la inteligencia humana, contraria a la sagrada escritura, enseñada en público y defendida con pertinacia». ${ }^{8}$ No obstante, la competencia de la Inquisición española desbordó los límites formales, interviniendo en casos que, en apariencia, nada tenían que ver con dicha definición. ${ }^{9}$

En el caso de la sodomía, el hiato con la herejía parece confirmarse a través de todas las disposiciones legales que, intermitentemente, habilitaron o prohibieron la intervención inquisitorial sobre la sodomía pero que, en cualquier caso, dejaban establecido que se trataba de dos fenómenos distintos. Por ejemplo, siguiendo el espíritu de la pragmática de los Reyes Católicos (1497) donde se establecía el mis-

\footnotetext{
${ }^{7}$ Cristian Berco: Sexual Hierarchies... 81.

${ }^{8}$ Marie-Dominique CHENu, «Ortodoxia y herejía. El punto de vista del teólogo», Herejías y sociedades en la Europa pre-industrial siglos XII-XVIII, J. Le Goff (comp.), 1-5, Madrid, 1987, 2.

9 José Antonio Escudero, Estudios sobre la Inquisición, Madrid, 2005, 39. 
mo castigo para la sodomía, la herejía y la lesa majestad, en 1505, Fernando de Aragón emitió una segunda pragmática, a través de la cual buscaba mitigar las ambigüedades de la primera y otorgar, lisa y llanamente, jurisdicción sobre la sodomía a la Inquisición. Según Henry Kamen, esta medida era, en realidad, una prosecución de las atribuciones que la vieja Inquisición había tenido respecto del delito. ${ }^{10}$ Sin embargo, en 1509, el Consejo de la Suprema y General Inquisición prohibía a los tribunales intervenir en casos de sodomía «si otras cosas no hay con ello que abiertamente sepan heregia», dejando la punición del delito a los tribunales civiles y eclesiásticos que, como se señalara, compartían jurisdicción sobre este asunto. ${ }^{11}$ No obstante, en 1524, un breve emitido por Clemente VII rectificaba el decreto y habilitaba a la inquisición aragonesa a intervenir en los casos de sodomía, involucraran o no el delito de herejía. ${ }^{12}$ La disposición papal fue una respuesta a la petición realizada por Sancho de la Caballería, una personalidad importante de la ciudad de Zaragoza, ante la Suprema. Allí, el declarante denunciaba a los inquisidores por haberlo procesado por «sodomía», no sólo porque se encontraba libre de culpa y cargo sino porque, además, los magistrados no contaban con competencias sobre el delito. Pero mientras la Suprema ordenaba detener el proceso hasta nueva orden, se inició una batalla judicial entre los inquisidores zaragozanos y el propio Sancho de la Caballería, que culminó con la apelación de ambos al papado. El resultado fue el breve papal emitido en 1524 en el que se otorgaba competencia sobre el delito de sodomía a todos los tribunales inquisitoriales aragoneses. Como dice Monter, «se había dado, en cierta medida accidentalmente, un paso fatal, y sus consecuencias se habían extendido más allá del reino de Aragón».13 No obstante, el procedimiento judicial del Santo Oficio seguía los mismos mecanismos que la justicia secular en los casos de sodomía: actuación del juez inquisidor por denuncia u oficio, prendimiento del sospechoso y confiscación de sus bienes, citación de los testigos, búsqueda de la confesión bajo tortura, etc. Incluso, una vez hallado culpable, la Inquisición entregaba al brazo secular al reo para su relajación. Con todo, los restantes tribunales inquisitoriales -incluido Castilla- estuvieron exentos de esa prerrogativa. ${ }^{14}$ Allí, la persecución del delito continuó a cargo de la justicia civil y eclesiástica como hasta entonces..$^{15}$

\footnotetext{
${ }^{10}$ Henry Kamen, La inquisición española, México, 1985, 271

${ }^{11}$ Ricardo GarCía CÁrCEL, Herejía y sociedad... 290.

${ }^{12}$ Archivo Histórico Nacional (AHN), Inquisición, 2347, Exp. 3.

${ }_{13}$ William Monter, La otra Inquisición: la Inquisición española en la Corona de Aragón, Navarra, el País Vasco y Sicilia, Barcelona, 1992, 328.

${ }^{14} \mathrm{El}$ intento de Felipe II por extender la jurisdicción inquisitorial castellana sobre la sodomía -que acompasaría su pragmática de 1592- fue denegado por el papa. Clemente VIII. Ricardo GARCíA CÁRCEL, «La Inquisición en la Corona de Aragón», Revista de la Inquisición, 7 (1987) 155.

${ }^{15} \mathrm{Si}$ bien la Inquisición constituía, luego de la monarquía, la única institución común a todos los reinos capaz de dar «unidad» a la fragmentación política y jurisdiccional, las disposiciones relativas a la sodomía ponían al descubierto, una vez, la heterogeneidad política y jurídica. John H. ElLIOT, La España imperial, 1469-1716, Barcelona, 1998, 111.
} 
Pero aun cuando el «conocimiento» de la Inquisición aragonesa sobre la sodomía constituyó un hecho fortuito y contingente, el mismo guardó una importante relación con el fenómeno de la herejía. ${ }^{16}$ Por ejemplo, si bien Sancho de la Caballería se comportaba como un cristiano ortodoxo y entre sus antepasados no había rastros de antecedentes heréticos, el hecho de ser descendiente de judeoconversos permitía echar un manto de dudas sobre las conductas y las creencias sexuales del furibundo opositor al Santo Oficio. ${ }^{17}$ La relación de los judíos con los actos sexuales execrables queda de manifiesto en la sátira antijudía de Francisco de Quevedo. Por ejemplo, en uno de los pasajes del Buscón, el poeta se refería a los judíos como «bujarrones» y «putos» y en Execración contra los judios, los calificaba de «abominables» y miembros de una «maldita y nefanda nación». ${ }^{18}$ Asimismo, el duque de Sessa que ofició como embajador de la Inquisición aragonesa en Roma, argumentaba que la sodomía era el «pecado de los moros»y, por lo tanto, solicitaba la jurisdicción sobre el delito, a fin de combatir la amenaza de las costumbres infieles. ${ }^{19}$ Por lo tanto, a pesar de que el conocimiento de la sodomía se basó en una decisión de naturaleza política y respondió a una serie de conflictos coyunturales, esa decisión también estuvo motivada e influenciada por ciertas ideas que hacían plausible la asociación de la sodomía con ciertos contextos heréticos, aun cuando sodomía y herejía constituían dos campos bien delimitados

\section{CONDICIONES TEOLÓGICAS PARA LA MUTUA IDENTIFICACIÓN}

Como se mencionara, el conocimiento de la Inquisición sobre algunos delitos asociados con la moral sexual, como la bigamia, la solicitación y la sodomía, constituyeron el corolario de la expansión desmesurada de sus competencias. No obstante, a pesar de no constituir herejías en sentido estricto, dichas prácticas sexuales podían entrañar cierto contenido herético. Por ejemplo, en el caso de la bigamia, los inquisidores entendieron que quienes la cometían sentían desprecio por el sagrado sacramento del matrimonio y, por lo tanto, seguían las reglas de los infieles en materia de regulación sexual. ${ }^{20}$ Lo mismo su-

16 Entre sus acepciones, el término «conocer» significaba intervenir judicialmente en una causa aunque también podía aludir al acceso carnal entre dos personas. Sebastián de CovarRuBias HorOzCO, Tesoro de la lengua castellana o española, Madrid, 1611.

17 William MONTER, La otra Inquisición... 326.

18 Francisco de Quevedo, La vida del buscón, Madrid, 2007, 56 o 94 y Execración contra los judíos, Barcelona, 2007, 15.

${ }^{19}$ Henry Charles LEA, A History of the Inquistion of Spain.V. 4, New York, 1825-1909, 363.

20 José Antonio Escudero, «La Inquisición Española», Historia 16, Número Extraordinario 1, (1986) 5-14.

Hispania Sacra, LXII

126, julio-diciembre 2010, 539-562, ISSN: 0018-215-X 
cedía con la solicitación, en la medida en que las palabras o los tocamientos deshonestos que se desarrollaran durante el acto confesional significaban una afrenta contra el sacramento y una inversión de los objetivos para los cuales había sido instituido por Cristo. Además, profanando la confesión, los clérigos solicitantes abonaban el rechazo y las críticas planteadas por los protestantes. ${ }^{21}$ Este tipo de razonamiento, aunque indirecto, puede constituir una línea interpretativa viable, a fin de dilucidar los posibles contornos heréticos contenidos en la práctica sodomítica. A continuación se sistematizan algunas condiciones teológicas que permitieron hacer inteligible un fenómeno con otro.

\section{a) La sodomía como idolatría}

Un primer elemento a tener en cuenta es la relación existente entre las prácticas sexuales prohibidas y la idolatría. La sodomía suele aparecer en los textos teológicos como atributo de los idólatras. Por ejemplo, Jerónimo de Estridón, en sus comentarios al libro de Ezequiel, equiparó a los habitantes de Sodoma con los gentiles. Sin dudas, su lectura procedía del exhaustivo conocimiento de las fuentes bíblicas de las cuales había oficiado como su traductor latino. Según el autor, el pecado de Sodoma, haber intentado «conocer»a los ángeles enviados por Dios, tuvo lugar debido a su desconocimiento de Yahvé y a su afición por los falsos dioses (Génesis 19, 1-17). ${ }^{22}$ Asimismo, como lo atestiguaban otros pasajes, la relación entre sodomía e idolatría era tan familiar que Dios amenaza al pueblo de Israel con la sal y el azufre, con los que castigo a Sodoma y a Gomorra, en caso de abandonarlo para «a servir a los dioses de esas naciones». (Deuteronomio 29, 17-22). No obstante, como señala Mark Jordan, las fuentes del Antiguo Testamento no son explícitas acerca de que la destrucción de Sodoma y el pecado de los sodomitas estuvieran vinculados con una trasgresión de naturaleza sexual; esa identificación, más bien, fue un proceso que se iniciaría con algunas cartas del Nuevo Testamento y, fundamentalmente, a partir de la interpretación patrística. ${ }^{23}$

Lo que sí queda de manifiesto tanto en varios libros del Antiguo Testamento como en algunas cartas del Nuevo es la aparición recurrente de lo que podría denominarse un complejo idolátrico. Éste no sólo consistía en la adoración de falsos dioses, sino en una serie de comportamientos licenciosos que de allí se desencadenaban. La sodomía se encontraba presente junto a otros delitos se-

\footnotetext{
57.

${ }^{21}$ Stephen Haliczer, Sexualidad en el confesionario: Un sacramento profano, Madrid, 1998, 54-

22 Sobre los significados del verbo «conocer» ver nota 14.

${ }^{23}$ Mark JoRdan, La invención de la sodomía en la teología medieval, Barcelona, 2000, 52-62.
} 
xuales -como las orgías, el incesto y la simple fornicación- pero también a la embriaguez y la gula, todos excesos vinculados a los pecados de la carne. (Deuteronomio 32, 5-6, 15-18; Jeremías 23, 10-14; 1 Pedro 4, 1-4; Gálatas 5, 19-23).

Agustín de Hipona también fue sensible a este compendio de pecados. En Espejo de la Sagrada Escritura, subraya aquellos pasajes bíblicos en los que aparecen claramente vinculados:

No consentirás que las hechiceras sigan con vida. Pénese con la muerte a quienquiera que tuviere ayuntamiento carnal con animales. Quien realice sacrificios en honor de los dioses -salvo sólo el Señor-, mátesele. (Éxodo 22, 18-20).

No entregarás a ninguno de tus descendientes para ser ofrendado al ídolo Moloch, ni profanarás el nombre de tu Dios. Yo, el Señor. No te ayuntarás con hombre como si de coito con mujer se tratara: es una abominación. No te ayuntarás con bestia alguna, ni te mancillarás con ella. La mujer no se prostituirá con ninguna bestia, ni se ayuntará con ella, porque es una depravación. No os mancilléis con ninguno de estos actos. (Levíticos 18, 21-24).

No os equivoquéis: ni fornicadores, ni idólatras, ni adúlteros, ni afeminados, ni sodomitas, ni ladrones, ni avaros, ni borrachos, ni calumniadores, ni salteadores poseerán el reino de Dios. (1 Corintios 6, 9-10). ${ }^{24}$

Las citas realizadas por Agustín podrían multiplicarse aunque resultan suficientes, a fin de poner de manifiesto cómo las prácticas sexuales contra natura, como la sodomía y la bestialidad, se insertaban en un contexto más amplio, en donde el ejercicio de la hechicería, el culto a los falsos dioses, la profanación a la persona divina, la embriaguez y un conjunto de conductas consideradas abominables y ajenas a la ley de Dios se combinaban.

Sin embargo, es importante destacar que este compendio de pecados tenía una tradición más antigua que la que pudieran elaborar los padres de la Iglesia con el objetivo de clasificar a los gentiles, infieles y paganos. De hecho, esos estereotipos y prejuicios se lanzaron primero contra las primeras comunidades de cristianos, cuyas prácticas religiosas eran vistas con recelo. ${ }^{25}$ Según los paganos, especialmente los romanos, los cristianos durante sus ceremonias:

(...) movidos por un impulso tonto, consagran y veneran la cabeza de un burro, el más abyecto de todos los animales (...) otros dicen que veneran los genitales del sacerdote que preside la ceremonia y los adoran como su se tratara de los genitales paternos... En cuanto a la iniciación de los nuevos miembros, los detalles son tan desagradables como bien conocidos. Un niño, cubierto de masa de harina para engañar al incauto, es colocado frente al novicio. Esta apuñala al niño con golpes invisibles (...) Luego -ies horrible!-

\footnotetext{
${ }^{24}$ Agustín de HiPona, El Espejo de la Sagrada Escritura en http://www.sant-agostino.it/spagnolo/speculum/index 2 .htm

${ }^{25}$ Sobre las sospechas contra los primeros cristianos ver Norman CoHn, Los demonios familiares de Europa, Madrid, 1980, 19-36.
}

Hispania Sacra, LXII

126, julio-diciembre 2010, 539-562, ISSN: 0018-215-X 
beben ávidamente la sangre del niño y compiten unos con otros mientras se dividen los miembros (...) Cuando el grupo se ha excitado por la fiesta y se ha encendido una lujuria impura entre los asistentes ya borrachos se le arrojan trozos de carne a un perro atado a una lámpara. El perro salta hacia adelante, más allá del largo de su cadena (...) Ahora, en la oscuridad, tan favorable a la conducta desvergonzada anudan los lazos de una pasión innominada, al azar. ${ }^{26}$

En el relato citado aparecen una serie de elementos como el infanticidio, el canibalismo, orgías sexuales, borracheras, etc. que recuerdan el complejo idolátrico enunciado en las escrituras y en la patrística. Todas estas prácticas eran consideradas por los romanos como contrarias a la ley natural, en la medida en que se encontraban fuera de los límites de la «civilización». Más allá de tratarse de atributos «fantásticos», estas acusaciones fueron eficaces para emprender la persecución de grupos amenazadores del orden social.

Pero si los cristianos fueron, en sus comienzos, una minoría vulnerable, hacia el siglo III, al crecer en el número de fieles, al incorporar a su fe a varias familias aristocráticas, al aumentar sus riquezas, en suma, al convertirse en una de las religiones más importante del imperio, fueron integrados y las persecuciones ya no se fundaron en las fantasías mencionadas. ${ }^{27}$ En los siglos posteriores, la relación se invertiría: los cristianos se transformarían en perseguidores y custodios de la ortodoxia religiosa, esto es, la nueva forma que asumiría la «civilización» y el orden social.

\section{b) La sodomía como brujería}

La persecución que emprendieron los cristianos no se tradujo en términos de civilización vs. barbarie, sino en términos de ortodoxia vs. herejía. En este sentido, el hostigamiento no se limitó a los infieles o paganos, alcanzando a aquellos miembros de la comunidad que no seguían, a pie juntillas, los dogmas establecidos por los padres de la Iglesia.

Si bien la acusación hacia los herejes rescató muchos atributos del complejo idolátrico descripto - canibalismo, infanticidio, sexualidad contra natura, adoración a falsos dioses- hacia el siglo XII, los teólogos adicionaron un nuevo ingrediente: la presencia del demonio. Mientras los primeros formaban parte de una tradición popular de larga data, el componente satánico constituyó una operación erudita que se cristalizó en una ciencia del demonio, la llamada demono-

\footnotetext{
${ }^{26}$ Testimonio de un pagano transcripto por Minucius Félix (c. siglo II) en Norman CoHN, Los demonios familiares... 19-20.

27 Ibidem, 35.
} 
logía. ${ }^{28}$ A partir de esta operación intelectual, los herejes ya no sólo contrariaban los dogmas eclesiásticos establecidos, sino que, más importante aún, se convertían en adoradores del demonio.

De este modo, una serie de sectas cristianas, como los valdenses y los fraticelli de opinione -todos cristianos piadosos- comenzaron a ser perseguidos por su pretendido culto al demonio entre los siglos XII y XV. ${ }^{29}$ En la visión de los teólogos, lo significativo de estos cultos era la centralidad que adquiría una serie de prácticas sexuales prohibidas, como las orgías, el incesto, la sodomía e, incluso, el bestialismo..$^{30}$ Esta asociación descansaba en la concepción del cuerpo -especialmente de la genitalidad- cuya debilidad lo convertía en un lugar propicio para la intervención del demonio. Por ejemplo, Gregorio Magno sostenía que la sodomía estaba íntimamente ligada a los genitales y cuando el diablo tomaba el control sobre estos últimos, provocaba sobre sus víctimas imágenes e impulsos que los llevaban a cometer diversos actos sexuales deshonestos, entre ellos, los de sodomía. ${ }^{31}$

Pero si en la demonología existió una figura que condensó la idea de culto al demonio y de sexualidad nefanda, esa fue la de la bruja. Por ejemplo, el juez y teólogo Martín del Río, a partir de las confesiones de las que había tomado parte, describía las reuniones de brujas y brujos -el sabbat- en los siguientes términos:

Una vez allí se enciende por lo general una gran hoguera, siniestra y espantable. El demonio preside sentado en su trono, en forma horrible, casi siempre de macho cabrío o de perro. Se le acercan para adorarle (...) Ofrécenle luego velas de pez o cordones umbilicales, y en señal de homenaje le besan el culo (...)

Cometidas estas maldades y execrables abominaciones, y otras parecidas, pasan a sentarse a las mesas, a celebrar un convite de manjares que proporciona el diablo. A veces bailan antes del banquete, otras después (...)

A veces desfilan ante el demonio con velas encendidas para besarle y adorarle, entonando en su honor cantos (...) de mucha obscenidad. O bien bailan al son de un tamboril o una flauta que toca un músico sentado en un árbol en Y (...). Es entonces cuando muy feamente se aparean con sus demonios amantes. ${ }^{32}$

${ }^{28}$ La misma asume un corpus coherente y sistemático recién hacia el siglo XV. Ver Robert MUCHEMBLED, Historia del Diablo, Buenos Aires, 2003 (2000), 49.

${ }^{29}$ Sobre el proceso de demonización de estas sectas ver Norman CoHN, Los demonios familiares... 55-89.

30 Por ejemplo, sobre los valdenses, se decía que en sus celebraciones se entregaban a orgías desenfrenadas donde copulaban hombres con hombres y mujeres con mujeres. Asimismo, en la orden de arresto a los Caballeros Templarios, se los acusaba de ser «como bestias de carga que acrecen de juicio y más aún, superan a las bestias irracionales por la asombrosa brutalidad que demuestran, pues se entregan a todos los crímenes más abominables con al sensualidad que incluso rechazan y evitan los mismos animales», haciendo referencia a la práctica contra natura. Norman CoHN, Los demonios familiares... 121.

${ }^{31}$ Mark JoRdan, La invención de la sodomía... 64-65.

${ }^{32}$ Fabián CAmpagne, «El largo viaje del Sabbat: La caza de brujas en la Europa Moderna». Estudio Preliminar al Tratado de las Supersticiones y Hechicerías, Fray Martín de Castañega, IX-CXII, Buenos Aires, 1997, XII.

Hispania Sacra, LXII

126, julio-diciembre 2010, 539-562, ISSN: 0018-215-X 
Si bien cualquier tipo de cópula carnal fuera de la unión sacramentada constituía un acto detestable, la cópula anal representaba su forma más acabada. En el sabbat, los demonios «conocían» carnalmente contra natura a los iniciados luego de que estos le rindieran el famoso «homenaje». Asimismo, dado que muchas veces el diablo tomaba la forma de macho cabrío, u otro tipo de animal, la iniciación se transformaba en un acto abierto de bestialismo. Pero la relación del pecado nefando con la brujería -forma extrema de herejía- no se le limitó únicamente a los actos sexuales que tenían lugar en la juntas de brujas y brujos.

Según la escolástica tomistas, la sodomía se incluía dentro de los pecados de lujuria que abarcaban todos los pecados de la carne cuyo objetivo era la búsqueda de placer con independencia de los naturales -y deseables- fines procreativos. A partir de esta definición, se construyó una escala de pecados sexuales que, de menor a mayor gravedad, incluía la simple fornicación, el estupro, el adulterio, el incesto y el sacrilegio. No obstante, el mayor grado de transgresión lo representaban los llamados «pecados contra natura», entre los que se encontraba la sodomía y el bestialismo, ya que no sólo priorizaban el placer a la procreación sino que, incluso, rechazaban de plano a esta última.

La gravedad de estos actos sexuales radicaba en el hecho de que, desde el derecho canónico, con particular influencia escolástica, se consideraba que Dios había creado todo lo existente y aunque su obra era total y perfecta, no tenía un sentido acabado sino que era un proceso en permanente desarrollo. ${ }^{33}$ Dentro de esa concepción, el varón, creado a su imagen y semejanza, portador de la simiente procreadora, capaz de hacer efectivo aquello de «creced y multiplicaos», se convertía en colaborador directo en la obra de la (pro) creación. Por lo tanto, cualquier desviación en la tarea encomendada por Dios se interpretaba como una alteración del orden creado. A partir de estas formulaciones, es posible identificar una de las primeras vinculaciones de la sodomía con el fenómeno de la brujería, en la medida en que tanto el brujo como el sodomita buscaban alterar los planes divinos. No obstante, mientras uno, a través de la realización de hechizos y maleficios, procuraba destruir el orden creado por Dios, el otro, a través de su comportamiento sexual, directamente, se negaba a colaborar con la creación de ese orden..$^{34}$

\footnotetext{
${ }^{33}$ Sobre la noción de «creación permanente» ver Francisco TomÁs y VALIENTE, «El crimen contra natura», Sexo barroco y otras transgresiones premodernas, Francisco Tomas y Valiente et Al., 33-55, Madrid, 1990.

${ }^{34}$ Kramer y Sprenger señalan que entre los maleficios ocasionados por brujas y brujos se encuentran el impedimento a los hombres para realizar el acto sexual y a las mujeres para concebir «por lo cual los esposos no pueden conocer a sus mujeres, ni éstas recibir a aquéllos». Al igual que los sodomitas, los maleficios conspiran contra el objetivo divino de la procreación. Heinrich KRAMER y Jacob SPRENGER, Malleus Maleficarum, Barcelona, 2005, 87.
} 
En segundo lugar, dado que a través de su práctica el brujo y el sodomita atentaban contra la obra de la creación, en realidad, no hacían más que actuar como instrumentos del demonio quien, desde su reinado infernal, no hacía más que contrariar los planes divinos. En este sentido, Heinrich Kramer y Jacob Sprenger entendían que las abominaciones realizadas por los brujos eran «a instigación del Enemigo de la Humanidad». ${ }^{35}$ Del mismo modo, a pesar de inscribirse en un contexto intelectual muy lejano al del estereotipo del sabbat, Pedro Damian, en su Libro Gomorreano, sostenía que «cuando un hombre se uno con otro hombre para cometer el pecado, no es ese un arrebato natural de la carne sino, solamente, el estímulo de la instigación diabólica». ${ }^{36}$

Por otra parte, el éxito de la «incitación» del demonio radicaba en operar sobre espíritus débiles. Por ejemplo, Martín de Castañega señalaba que sus principales seguidores se reclutaban de entre los «flacos y pecadores». ${ }^{77}$ Para el fraile franciscano, aquí radicaba la clave para entender «por qué destos ministros diabólicos hay más mujeres que hombres», después de todo, eran más curiosas en el saber -aun cuando su naturaleza se los impedía- más «parleras» y torpes para guardar secretos, vengativas e iracundas, incapaces de controlar sus apetitos carnales, etc. ${ }^{38}$ En la medida en que los sodomitas fueron definidos en términos similares al «sexo débil», es decir, que fueron feminizados, no es de extrañar que también fueran identificados como presas fáciles para la acción del demonio. Refiriéndose al fenómeno de la sodomía, Pedro Damián sostenía que «la hábil maquinación del diablo ha inventado este grado de libertinaje de modo que, cuánto más alto el espíritu desafortunado continúa en el, mucho más bajo es arrojado en la profunda fosa del infierno». ${ }^{39}$ Pero esa flaqueza espiritual se correspondía con una debilidad de la carne que, como se mencionara, constituía el talón de Aquiles por donde atacaba el demonio. En el caso de la bruja, esa volubilidad sexual estaba vinculada con una serie de estereotipos y prejuicios acerca de la naturaleza de las mujeres, según la cual, la sexualidad femenina, además de peligrosa, era insaciable y voraz. ${ }^{40} \mathrm{El}$ sodomita, por su parte, era considerado un individuo de apetencias genitales desenfrenadas y cuyo uso desordenado de lo venéreo lo arrojaba a dirigir su deseo sexual fuera de los marcos de la denominada ley natural. En este sentido, ambos personajes, en vir-

\footnotetext{
${ }^{35}$ Heinrich Kramer y Jacob SPRENGer, Malleus meleficarun... 87.

36 Pedro DAMIÁN, Liber Gomorrhianus, TFO-SWIF, http://lgxserve.ciseca.uniba.it/lei/tfo/public/9/irenezavattero41_9.pdf ,87.(Traducción personal del italiano al español)

${ }^{37}$ Martín CASTAÑEGA, Tratado de las Supersticiones... 27.

38 Ibidem, 63.

39 Pedro DAMIÁn, Liber Gomorrhianus... 84.

${ }^{40}$ María TAusiEt, «Avatares del mal: el diablo en las brujas»: El diablo en la edad moderna, María TAusiet y James S. Amelang (eds.), Madrid, 2004, 55.
}

Hispania Sacra, LXII

126, julio-diciembre 2010, 539-562, ISSN: 0018-215-X 
tud de su flaqueza espiritual y sexual, reunían las condiciones necesarias para que el demonio pudiera desplegar sus influencias con mayor efectividad.

Más allá de la «persuasión» del demonio y de la «debilidad» de la carne y el espíritu, tanto el brujo como el sodomita adherían activamente al proyecto diabólico. En ese escenario, una de las nociones centrales fue la de «pacto», la cual, en cierta medida, también equiparaba a los sodomitas con los brujos. En el caso de los brujos, la idea de pacto era mucho más clara, en la medida en que los demonólogos consideraban que el poder para realizar los maleficios procedía de la invocación explícita al demonio y la consecuente sumisión a su voluntad. ${ }^{41}$ En cambio, en el caso de los sodomitas no mediaba un pacto explícito con el demonio aunque, a través de su práctica, se podía inferir los vínculos con Satanás. De hecho, lo mismo acontecía con algunos hechiceros, a quienes si bien no se les podía atribuir una invocación verbal al demonio o el ofrecimiento de sacrificios humanos, los demonólogos consideraban que, de virtud de su práctica, existía un pacto de carácter implícito. ${ }^{42}$ Por lo tanto, mientras en un caso la adhesión al proyecto del demonio se manifestaba de manera abierta -se sellada a sangre y fuego en la noche del sabbat- en el otro, adquiría un ribete más sutil $\mathrm{o}$ indirecto aunque no por eso menos repudiable.

Otro aspecto a tener en cuenta fue el hecho de que tanto el brujo como el sodomita podían considerarse súbditos del demonio, ya que aun cuando existía una idea de pacto, éste se definía en términos asimétricos. ${ }^{43}$ En este sentido, si bien el diablo podía facilitar la obtención de riquezas, sabiduría o deleites carnales, el contra don implicaba, indefectiblemente, la sujeción total y completa a su tiranía. En el caso de la brujería, como se mencionara, sus vasallos llegan a la máxima humillación al propinarle el «ósculo infame» como forma de homenaje y «muestra de su dominio y señoría». ${ }^{44}$ En el caso de la sodomía, Pedro Damián expresa que el sodomita no es otra cosa que un «esclavo de la férrea ley diabólica». ${ }^{45}$ Dentro de ese universo conceptual, la penetración sexual actuaba como una metáfora de la subordinación. Como se mencionara, durante el sabbat, el diablo conocía carnalmente a los brujos y, por general, lo hacía a través del llamado «sieso trasero». Esta forma de intercambio sexual no sólo significaba un desprecio total por la obra de la creación sino también la forma más hu-

${ }^{41}$ James S. AmelANG, «Durmiendo con el enemigo: el diablo en los sueños», El diablo en la edad moderna... 337.

${ }^{42}$ Walter StePhen, Demon Lovers: Witchcraft, Sex, and the Crisis of Belief, Chicago, 2003, 325.

${ }^{43}$ Norman Cohn muestra como antes de la creación del estereotipo del sabbat el diablo servía de un modo u otro al ser humano que lo había conjurado. Por el contrario, en los juicios por brujería de los siglos XVI y XVII se produce una inversión de los términos: de sirviente, el diablo se transforma en amo. Norman COHN, Los demonios familiares... 294.

${ }^{44}$ Martín CASTAÑEga, Tratado de las Supersticiones... 81.

${ }^{45}$ Pedro Damián, Liber Gomorrhianus... 93-94. 
millante de sumisión. Tanto a través de la penetración «natural» como «antinatural», el diablo reafirmaba su rol de agente y dominante y, de este modo, imponía su voluntad sobre la realidad humana ${ }^{46} \mathrm{Si}$ bien la relación entre el diablo y los brujos era de reciprocidad, existía un vínculo jerárquico entre ambos, en la medida en que uno mandaba y los otros obedecía, uno otorgaba mientras los otros tomaban. En este sentido, poder y sumisión eran dos elementos claves de esa relación, cuya cristalización más patente era el ritual del beso en las partes intimas del demonio durante el aquelarre. ${ }^{47}$ Por su parte, los sodomitas, al asumir el rol de «pacientes» y rechazar el carácter «penetrante» de su género, también daban cuenta de su naturaleza sumisa y dominada y aunque no mediara una invocación explícita al demonio, sus actos no podían estar movilizados más que por él.

Otro elemento que marca la cercanía entre la brujería y la sodomía es la identificación de ambos fenómenos como una suerte de contra-iglesia. Una vez más, Martín de Castañega es taxativo en este punto:

Dos son las iglesias deste mundo: la una es católica, la otra es diabólica. La iglesia católica es la congregación de todos los fieles católicos, la cual es una, por un Dios que todos adoran; por una fe, que todos confiesan; por un batismo que todos reciben. La iglesia diabólica es generalmente toda infidelidad que está fuera de la iglesia católica; la cual no es propiamente una, porque no creen ni adoran un Dios verdadero. 48

La iglesia del demonio constituía la contratara de la iglesia católica: mientras una poseía sacramentos, la otra poseía execramentos, mientras una era guiada por sacerdotes, la otra tenía hechiceras por ministros, mientras una se congregaba en celebraciones eucarísticas, la otra urdía sus infamias en los aquelarres, etc. En el mismo sentido, Pedro Damián reconocía otra parodia eclesiástica: mientras la iglesia católica prescribía el buen comportamiento de sus fieles a través del derecho canónico, «muchas otras cosas falsas y sacrílegas se encuentran insertas en el canon sagrado de la astucia del diablo», entre ellas, la sodomía. ${ }^{49} \mathrm{Sin}$ embargo, Pedro Damián fue menos optimista que Catañega respecto a la unidad de la iglesia católica. Su Libro Gomorreano constituyó una advertencia al papa León IX sobre la expansión de la sodomía en la propia iglesia:

La suciedad sodomítica se insinúa como un cáncer en la orden eclesiástica, de hecho, como una bestia sedienta de sangre que actúa cruel sobre el redil de Cristo con la libre audacia, tanto que sería mucho mejor haber sido aplastado por el yugo de la milicia secular

\footnotetext{
46 Walter Stephen, Demon lovers... 54.

47 Beatriz Moncó Rebollo, «Demonios y mujeres: historia de una transgresión», El diablo en la Edad Moderna... 190.

48 Martín Castañega, Tratado de las Supersticiones. 39.

49 Pedro Damián, Liber Gomorrhianus... 100.
} 
que someterse, tan liberadamente, a la ley del hierro de la tiranía diabólica bajo la cobertura de la religión.

No obstante, lo más significativo del opúsculo fue la identificación de una contra-iglesia sodomítica surgida desde las propias entrañas de la iglesia católica y no como producto de una amenaza externa. Muchos miembros de la clerecía y la feligresía formaban parte de una suerte de comunidad sodomítica, en la que se amparaban para continuar en el pecado. En este sentido, como observa Mark Jordan, lo que obsesionaba al autor del opúsculo era la existencia de una iglesia de Sodoma dentro de la iglesia de Dios..$^{50}$ Obispos sodomitas protegían a los sacerdotes sodomitas y estos, a su vez, eran complacientes con sus hijos de confesión. Pedro Damián sospechaba de una jerarquía oculta que poseía medios de gobiernos y reclutamiento propios..$^{51}$

En séptimo lugar, es importante destacar que en función de sus propias prácticas, el brujo y el sodomita -como miembros de la «otra iglesia»- constituían individuos que marcaban una clara ruptura con la comunidad que, durante el período estudiado, no es otra cosa que la comunidad de creyentes..$^{52} \mathrm{~A}$ través de la hechicería o las prácticas sexuales nefandas, ambos infamaban tanto a Dios como a su prójimo, alejándose del cuerpo social que estructuraba y daba sentido a la sociedad. Sin embargo, no constituían simples «parias», la misma noción de «otra iglesia» permitía reagruparlos y auto-reconocerse como miembros de una misma sociedad. La idea de «pacto colectivo» fue central para la definición del estereotipo de la brujería y permitió identificar a las brujas y brujos como miembros de una misma «secta». El sodomita también constituyó un individuo marginal y, en ciertas ocasiones, logró formar redes y espacios colectivos que, al mismo tiempo que lo amparan del fuego secular, ahondaba las distancias respecto de la comunidad mayor. Por ejemplo, en un proceso criminal por sodomía seguido en Nueva España en 1657, se pone en evidencia la existencia de espacios de congregación de sodomitas donde desarrollaban sus fiestas y celebraciones, parodiando las liturgias católicas u ocultándose detrás de ellas:

(...) los susodichos, según pareze de los autos, cometieron este pecado señaladamente los dias de nuestra señora, de lso sanctos apostoles y otras festibidades de la yglesia

${ }^{50}$ Mark JoRDAn, La invención de la sodomía... 80.

${ }^{51}$ En un proceso por brujería en 1459 en, dos dominicos que jugaron un papel muy importante durante el juicio, sostenían que muchos obispos y cardenales eran brujos y que la tercera parte de la cristiandad adoraban en secreto al demonio. Sobre este proceso ver Norma CoHN, Los demonios familiares...292.

${ }^{52} \mathrm{H}$.-I. Marrou advierte que la comunidad de creyente se presenta durante el medioevo -y puede extender a la temprana edad moderna- como la forma mas elevada de comunidad que se confunde y superpone a la comunidad social. Ver H.-I. MARROU, «La herencia de la cristiandad», Herejías y Sociedades... 33 . 
porque los mas de ellos tenian en sus oratorios las ymagenes de nuestra señora y demas santos referidos y con ocasion de zelebrar sus fiestas se conbidavan los unos a los otros $(\ldots) .53$

Otra de las nociones que compartieron los fenómenos de la sodomía y la brujería es la idea de «complot». La mayoría de los jueces que intervinieron en las cazas de brujas compartían la creencia de que las susodichas formaban parte de una conspiración satánica que debía ser desarticulada. Respecto de la sodomía, los jueces -no necesariamente inquisitoriales- tenían una percepción similar. Por ejemplo, en el proceso novohispano que ha sido citado, el juez interviniente se refiere al delito de sodomía en términos de un «complot» y agradece a Dios «aver cogido esta complicidad y comenzado a atajar este canzer que tan cundido y estendido estava en estas provincias». ${ }^{54}$ Lo central en este tipo de procesos -por brujería o por sodomía- es el empeño por dilucidar los cómplices del delito, de cuyo conocimiento parecería depender la preservación de la cristiandad. Esta preocupación llevó a la utilización de todo tipo de métodos, entre ello, la tortura que se convirtió en la herramienta más efectiva para las denuncias en cadena. Por ejemplo, en Wüttemberg, con una población de apenas 650 habitantes, en menos de un año, fueron ejecutados 50 personas en ocho autos de fe masivos. ${ }^{55}$ En el proceso de Nueva España, la catarata de delaciones fue tal que, además de las 14 personas relajadas en el mismo día y las 9 que permanecieron en prisión a la espera de sus sentencias, se publicó, a través de edictos y pregones, la captura de casi 100 sospechosos por sodomía a partir de las acusaciones de los reos.

Otro aspecto que vinculó la figura del brujo a la del sodomita, fue la existencia de «marcas» que evidenciaban su pacto con el demonio. Dada la dificultad para comprobar el delito de brujería, en la medida en que la maldad se alojaba en el interior del brujo, los jueces apelaron a las marcas corporales y a la sexualidad pervertida como pruebas. Las mismas afirmaban, por un lado, la presencia física del diablo y, por otro, la culpabilidad del acusado. ${ }^{56}$ Otro tanto sucedía con la comprobación del delito de sodomía, no en vano la pragmática real de Felipe II en 1598 establecía que «por ser de su naturaleza de tan dificultosa probanza; Mandamos (...) que los que lo cometiesen, fuesen condignamente castigados, aunque el dicho delito no fuese probado por testigos contestes, sino por otras formas establecidas y aprobadas en Derecho». ${ }^{57}$ Asimismo, la prueba de

\footnotetext{
53 Archivo General de Indias (AGI), México 38, N.57, 3, f. 7.

54 AGI, México 38, N.57, 2, f. 2.

55 Norman CoHn, Los demonios familiares... 319.

56 Sobre las marcas corporales ver Robert Muchembled, Historia del Diablo... 77-87 y María TAUSIET, Avatares del mal... 61.

${ }^{57}$ Novísima Recopilación de Leyes de España, Madrid, 1805,Título XXX, Ley II. 
la sexualidad pervertida del brujo o la bruja presentaba relaciones directas con el fenómeno de la sodomía, en la medida que la perversión a la que remitía abarcaba las relaciones incestuosas, el bestialismo y la sodomía misma. En este sentido, la perpetración de prácticas sexuales prohibidas por parte de los sodomitas, los ponía bajo sospecha de algún tipo de relación con el demonio.

Otro elemento a tener en cuenta fue la creencia en el desencadenamiento de catástrofes, daños y calamidades a partir de la acción de brujos y sodomitas, aún cuando los mismos se produjeran por motivos opuestos. La presencia de brujos o de una secta de adoradores del demonio era posible de elucidar a partir de una serie de fenómenos -negativos- que azotaban a una aldea o comunidad. Por ejemplo, el Malleus Maleficarum describe algunos de los daños que podían propinar la acción de las brujas:

Han matado niños que estaban aún en el útero materno, lo cual también hicieron con las crías de los ganados; que arruinaron los productos de la tierra, las uvas de la vid, los frutos de los árboles; más aun, a hombres Y mujeres, animales de carga, rebaños y animales de otras clases, viñedos, huertos, praderas, campos de pastoreo, trigo, cebada y todo otro cereal; 58

Pero mientras todas estas calamidades son posibles gracias a la intervención del demonio, en el caso de la sodomía las mismas son producto de la ira divina. Por ejemplo, el conocido pasaje del Génesis relata como Dios castigó a los moradores de Sodoma y Gomorra, enviándoles fuego y azufre a fin de destruir sus ciudades, sus campos y su ganado. Pablo de Hungría se inspiró en este pasaje para plantear la relación entre daño y sodomía y, en la Summa de la Penitencia, advertía que «la ley dice que debido a este crimen vienen hambre, plagas y terremotos. De nuevo los sodomitas son los adversarios de Dios y asesinos y destructores de la humanidad». ${ }^{59}$ Asimismo, en un proceso seguido por sodomía en 1608 en la ciudad de Charcas, el arcediano de la catedral señalaba la existencia de «signos» que evidencian la furia de Dios:

Le aviso del mal que puede venir y mire que Dios nuestro señor a mostrado señales que dicen que saliendo don Diego de la comedia (...) vieron el señor don Juan de Mendoza y sus criados y otros muchos que le cayeron de la capa una centella o centellas grandes de fuego de la capa de que quedaron todos los que vieron escandalizados y que ayer bajando vuestra merced las escaleras del choro se le encendio un globo de fuego en la falda lo qual vieron el señor chantre y el señor maese escuela de que estava escandalizada toda la tierra. ${ }^{60}$

\footnotetext{
${ }^{58}$ Heinrich Kramer y Jacob SPREnger, Malleus Maleficarum... 4.

${ }^{59}$ Citado en Mark JoRdAn, La invención de la sodomía ... 148.

${ }^{60}$ AGI, Charcas 140, s/f.
} 
Para finalizar, es importante notar la presencia del «fuego redentor» como medio de escarmiento divino hacía los sodomitas y los brujos. Es sintomático que ambos delitos -junto con el de herejía y el de traición- conllevaran el mismo y más crudo de los castigos: la hoguera. Por ejemplo, una pragmática de los Reyes Católicos emitida en 1497 establecía que «cualquier persona, de cualquier estado, condición preeminencia o dignidad que sea, que cometiere el delito nefando contra naturam seyendo en el convencido por aquella manera de prueba, que según Derecho es bastante para probar el delito de heregia o laesae Majestatis, que sea quemado en el lugar, y por las Justicia a quien perteneciere el conoscimiento y punición de tal delito». ${ }^{61}$ Esta situación jurídica llevaría a acrecentar la vinculación -cuando no la identificación- de la brujería con la sodomía y de ésta con la herejía. Según Muchembled, las ejecuciones por pecado nefando se multiplicaron en Francia y Holanda durante aquellos momentos en que los procesos por brujería también se expandían. ${ }^{62}$ Para el autor, ambos fenómenos proceden del mismo impulso de culpabilización que buscaba persuadir a la bestia que tanto brujos como sodomitas llevaban adentro.

\section{c) La sodomía como factum hereticale ${ }^{63}$}

Dado que la herejía, como se mencionara, se definía como una proposición libremente elegida que contrariaba a la sagrada escritura, su forma de identificación era a través de la exposición en público del error. En este sentido, una de las preocupaciones centrales para la ortodoxia fue cómo descubrir al hereje en aquellos casos donde no existía una formulación errónea de manera explícita y verbal.

Para morigerar este peligro, Juan XXII emitió la Bula Super Illius Specula (1320) a través de la cual, al asimilar la magia ritual y ceremonial a la herejía, permitió la creación de una nueva noción: la de factum hereticale. Uno de los objetivos centrales de esta categoría fue brindar, frente a la ausencia manifiesta de error, las pruebas necesarias para el descubrimiento de la herejía a través de la propia práctica de los herejes. Dado que en muchos casos la herejía se apoyaba en el silencio, el ocultamiento y la disimulación-después de todo, la maldad tenía su mejor escondite en la interioridad de los individuos- era urgente idear mecanismos eficaces que pudieran desmantelar el avance de la heterodoxia, cuando no de la apostasía. Este apego a la «factualidad» marcó la derrota del «hecho débil» de los éticos de la intención -para quienes lo importante era lo

\footnotetext{
${ }^{61}$ Novísima Recopilación de las Leyes de España, Libro XII, Título XXX.

${ }^{62}$ Robert Muchembled, Historia del Diablo... 80.

${ }^{63}$ Quiero agradecer al Dr. Fabián Campagne por advertirme acerca de la utilidad de este concepto para mi investigación.

Hispania Sacra, LXII

126, julio-diciembre 2010, 539-562, ISSN: 0018-215-X
} 
que había en el interior- frente al «hecho duro» sostenido por los tribunales de investigación. Por lo tanto, la noción de factum hereticale aportaba la prueba jurídica necesaria -siempre dificultosa de encontrar en la definición tradicional de herejía- que permitía la persecución y el procesamiento judicial de los herejes. De este modo se producía una desvinculación entre fe y error hasta entonces dominante.

Por lo tanto, como plantea Alain Boureau, la bula de Juan XXII constituyó una ruptura epistemológica al transformar al «hecho» en un argumento esencial de certidumbre. ${ }^{64}$ Ya no era necesaria la existencia de una proposición verbal pública para el descubrimiento de la herejía, ya que los mismos «actos» venían a denunciar la opinión del hereje. En este escenarioo, la bula papal transformó la herejía de «un creer» en «un hacer».

Asimismo, la Super Illius Specula fue una rectificación de la bula Accusatus emitida por Alejandro IV en 1260. En la misma, el papa limitaba la intervención de la jurisdicción inquisitorial en delitos mágicos, salvo que los mismos «huelan manifiestamente a herejía». Esta formulación, recuerda a la ya mencionada intervención de la Suprema en 1509 cuando, a través de un decreto, prohibía a la inquisición proceder en los casos de sodomía si no involucraba abiertamente cuestiones heréticas. Quince años más tarde, un breve de Clemente VII habilitaba el conocimiento de la Inquisición sobre asuntos de sodomía, existieran o no delitos de herejía. Si bien según estas legislaciones, en un principio, tanto la brujería como la sodomía no constituían en si mismas herejías, esas diferencias iniciales se fueron diluyendo, más o menos progresivamente, a lo largo de los siglos. En ambos casos, la Super Illius Sepecula jugó un papel central. En lo que respecta a la brujería, la relación fue explícita y directa, ya que la bula papal asimilaba la magia ritual a la herejía. En el caso de la sodomía, aunque el vínculo estuvo más mediado, no obstante, a través de la noción de factum hereticale, la Super Illius Specula señalaba la potencialidad herética de la sodomía y sentaba las bases para su futura asimilación con la herejía.

En este sentido, el sodomita, aun cuando no manifestara abiertamente una proposición errónea, sus mismos actos delataban sus opiniones, en este caso, vinculadas a la creación y al orden divino. Por otra parte, dado que actuaban en secreto - a causa de la amenaza atenta del brazo secular- era difícil poder identificarlos, por lo que determinados actos -como el amaneramiento, la soltería, la amistad profunda con otro hombre, entre otras- podían actuar también como pruebas suficientes para transformarlos en «sospechosos», una de las nociones centrales de la Super Illius Specula. Por ora parte, la frecuencia en la perpetración del delito -la repetición del acto- podía convertirlos en sospechosos sim-

64 Alain Boureau, Satan Hérétique. Naissance de la démonologie dans l'Occident médiéval (1280-1330), París, 2004, 41. 
ples, vehementes o muy vehementes, parangonando la misma gradación que la herejía propositiva.

\section{LA SODOMÍA COMO HEREJÍA Y LA PRAXIS INQUISITORIAL}

A partir del análisis realizado, puede sugerirse que la importancia de la práctica sodomítica en el complejo idolátrico tradicional, las semejanzas entre brujos y sodomitas y la noción de factum hereticale, constituyeron algunos de los fundamentos que contribuyeron a la progresiva identificación entre la sodomía y la herejía. Pero aun cuando esas formulaciones pudieron operar como condiciones teológicas de posibilidad, la identificación de la sodomía con la herejía dependió, en gran medida, de la interpretación y de la actuación, especialmente, de los jueces inquisidores y, en menor medida, de los reos. Por ejemplo, de las doce causas incoadas en el Virreinato del Perú que contienen acusaciones o autodenuncias de haber cometido actos sodomíticos, sólo cuatro no tienen ningún tipo de relación con actos o proposiciones heréticas, mientras que, en las restantes, los actos de sodomía aparecen como un aditivo, muy grave, por cierto, a las acusaciones de nigromancia, pacto con el demonio, iluminismo, luteranismo, etc. En este sentido, pareciera que los inquisidores limeños no procedieron contra los crímenes nefandos como lo hicieran sus colegas aragoneses a partir del breve papal de Clemente VII. Por el contrario, su actuación fue más cercana a lo establecido por la Suprema que, en 1509, prohibía a los tribunales inquisitoriales españoles intervenir en casos de sodomía «si otras cosas no hay con ello que abiertamente sepan heregia».65

En ese marco, si bien los inquisidores se preocuparon por los actos de sodomía en sí mismos, también buscaron determinar el nivel de error que podía contener su realización, ya que aun cuando la noción de factum hereticale permitía hacer inteligible las herejías ocultas, los magistrados prefirieron arrancar una confesión verbal. Por ejemplo, luego del reconocimiento de haber cometido el nefando crimen, los inquisidores que conocieron en el caso de Fray Sebastián de Oviedo de la Orden de Santo Domingo (c.1584) exhortaban al reo a que «declarase clara y abiertamente si savia que conforme a la le ley de Dios por el sexto mandamiento esta prohivida toda copula carnal excepto la copula con muger propia». ${ }^{66}$ Del mismo modo, en la causa iniciada en 1571 contra el dominico Francisco de la Cruz no sólo consideraban que por haber cometido el pecado nefando «según las reglas de teolugia ha hecho en pensamientos, palabras y

65 Ricardo García CÁRCEL, Ricardo: Herejía y sociedad en el siglo XVI. La inquisición en Valencia, 1530-1609, Barcelona, 1980, 290.

${ }^{66}$ AHN, Inquisición, Libro 1027, f. 233.

Hispania Sacra, LXII

126, julio-diciembre 2010, 539-562, ISSN: 0018-215-X 
obras muchos pecados mortales contra el sesto mandamiento», sino que, además, creía que esos actos denotaban la creencia de que aquello no era pecado mortal como, finalmente, admitió el reo. ${ }^{67}$ Otro tanto aconteció con Fray Juan de Maldonado (c. 1590), de la misma orden, a quien un novicio denunció por haberle realizado actos torpes y tocamientos deshonestos. Según el joven, el reo «le dixo que si queria que tuviesen polucion en sus propias manos cada uno con si y que diciendole el dicho novicio que no queria porque era pecado mortal, este reo le avia respondido que no era pecado mortal sino venial».68 Esta afirmación guardaba para los inquisidores una seria sospecha de error y, en este sentido, aunque trataron de determinar qué tipos de actos había realizado Maldonado, sus preguntas giraron en torno a las palabras que había formulado al novicio, en especial, «si sabia que todo acto venereo fuera del matrimonio era pecado mortal». .9

Otro de los elementos cercano a la sospecha de herejía en los procesos inquisitoriales limeños fue la denuncia acerca de la existencia de una Iglesia compuesta y dirigida por sodomitas como. Sin embargo, en estos casos, no fueron los inquisidores los preocupados por descubrir y desmantelar la supuesta estructura eclesiástica paralela sobre la que Pedro Damián había versado varios siglos antes. Por el contrario, fueron los mismos reos acusados de sodomitas quienes alzaban la voz para manifestar los actos nefandos de fraile, prelados y hasta sumos pontífices. Por ejemplo, el agustino Juan Pablo de Borja (1584), realizaba una crítica mordaz al conjunto de su orden, cuyos frailes, aseguraba, «no eran cristianos ny creian en dios sino luego les avian de quemar», aludiendo a la inclinación por la sodomía que reinaba en el claustro. ${ }^{70}$ También afirmaba que en Roma había sido testigo de como «los cardenales eran sodomitas con sus pajes y con monjas y otras mugeres contra natura [y] que el sumo pontifice Gregorio decimo tercio que entonces reynaba era mas sodomita que otros y tenia un hijo». ${ }^{71}$ Del mismo modo, Fray Francisco de la Cruz, en su «desmesurada» lucha contra el celibato clerical, confesaba que Dios había reprendido «al señor arçobispo de los Reyes a bozes por la boca de este reo diziendo puto viejo arçobispo traydor», poniendo al descubierto las aficiones sexuales del prelado y la doble moralidad de la institución. ${ }^{72}$ Si bien todas estas denuncias procedían de personas eclesiásticas sindicadas de sodomitas, es decir, de individuos que podían hablar con «conocimiento de causa» acerca de la «infección» sodomítica en el seno de la Iglesia, lo cierto es que los inquisidores prefirieron hacer

\footnotetext{
${ }^{67}$ AHN, Inquisición, Libro 1032, f. 55v.

${ }^{68}$ AHN, Inquisición, Libro 1027, f. 273v.

${ }^{69}$ AHN, Inquisición, Libro 1027, f. 273v.

${ }^{70}$ AHN, Inquisición, Libro 1028, f. 136v.

${ }^{71}$ AHN, Inquisición, Libro 1028, f. 136v

72 AHN, Inquisición, Libro 1032, f. 58.
} 
caso omiso a las denuncias y calificar a los acusados de luteranos, en virtud de las críticas que realizaban contra las autoridades de la Iglesia. ${ }^{73}$

La presencia del demonio también estuvo presente en varios de los casos incoados por el tribunal peruano. A lo largo de las audiencias mantenidas con los inquisidores, varios de los acusados aseguraban que los tocamientos, poluciones y accesos nefandos que habían protagonizado habían sido obra del demonio. Como se mencionara, este tipo de alegato formaba parte del pensamiento demonológico de la época, según el cual, el diablo procuraba hacer efectivo sus planes destructores a través de la manipulación del costado más vulnerable de la humanidad: la carne. Por ejemplo, en el proceso seguido contra el citado Fray Sebastián de Oviedo, el reo declaraba que «un demonio lo atormentava y no le dexava rezar las horas canonicas ni ir a maytines y le necesitava a actos torpes y feysimos en sus miembros lo qual no tenia por pecado mortal diziendo no tenia en aquello libertad». ${ }^{74}$ Por su parte, Alonso de Rentería de la Orden de San Francisco (c.1597) manifestaba a los inquisidores que a lo largo de su carrera, primero como colegial, luego como novicio y, finalmente, como fraile, había tenido tocamientos deshonestos y acceso sodomítico con más de 150 personas. No obstante, había procurado no revelar sus pecados ante sus confesores y «la causa principal de haver cometido este mal de no tratar verdad en la confesión fue encubrir un vicio diabólico y nefando en que hasta agora he vivido y es conmigo mismo y con terceras personas». ${ }^{75} \mathrm{La}$ presencia del demonio también puede observarse en la confesión del agustino Pedro de Peñalosa quien, para «curar su llaga y descargar su conciencia», se presentó ante los tribunales del Santo Oficio limeño. Allí, declaraba que luego de confesar a un penitente que había manifestado tener auto poluciones:

le llego a este reo a tentar el demonio y a inquietar de saver como se tenian poluciones y asi despues de aver confesado pasado mas de una hora, comulgando e oydo misa el muchacho, le sitaba y llebaba a su celda y le deçia este reo queria ver como se tenian las poluciones que lo deseaba y que a ynstancias de este reo sacaba el muchacho sus partes verendas y este reo se las manoseaba. ${ }^{76}$

Como puede observarse, el demonio aparece como el instigador de los actos de sodomía mientras que los reos son apenas un instrumento de los designios del maldito. Pero aun cuando este tipo de alegatos podía constituir una suerte de «coartada» de los acusados, a fin de eximirse del castigo correspondiente, también es cierto que los jueces inquisidores compartían, en cierto grado, las mismas creencias. Por ejemplo, los magistrados que conocieron en la causa de Sebastián de Oviedo,

\footnotetext{
${ }^{73}$ Las resoluciones de los calificadores sobre los casos de Fray Francisco de la Cruz y Fray Juan Pablo de Borja pueden verse en AHN, Inquisición, Libro 1032, f. 67 y Libro 1028, f. 137v.

74 AHN, Inquisición, Libro 1027, f. 223v.

75 AHN, Inquisición, Libro 1036, f. 312.

76 AHN, Inquisición, Libro 1032, f. 476.
}

Hispania Sacra, LXII

126, julio-diciembre 2010, 539-562, ISSN: 0018-215-X 
inquirieron al fraile para saber «acerca si se le ofrecio el diablo a que tuviere acceso carnal con el tomando el demonio figura de muger o de hombre», a lo que el reo respondió que si y en muchas oportunidades..$^{77} \mathrm{La}$ consulta resultaba pertinente, ya que si bien la teoría de los íncubos y súcubos aludía, por lo general, a violaciones y asaltos sexuales hacia mujeres, los teólogos Kramer y Sprenger también sostenían que los demonios eran capaces de cometer inmundicias como los vinculados a la sodomía y a la emisión de semen por el vaso indebido. ${ }^{78}$ Con todo, los inquisidores limeños fueron cautos con este tipo de afirmaciones, ya que si bien comulgaban con la teoría demonológica y creían en el pacto explícito e implícito con el demonio, también consideraban que algunos de los testimonios de los reos no eran más que «desatinos». Por ejemplo, en el caso de Pedro de Coronado, quien no sólo confesó haber cometido el pecado nefando con Juan Pablo Borja y con otras personas sino que también admitió haber injuriado a Dios de puto, manifestaba ante los inquisidores que esas acciones «avian sido gravisimas como tenia confesado y que para ello avia dado mucha parte el demonio». ${ }^{79}$ Pero no contento con los crímenes cometidos, el demonio, además, lo había inducido a burlar la justicia divina y humana fingiendo demencia, según el reo, «porque lo hazia con muy mal animo y mala yntención pretendiendo con ello la escusa del castigo que por sus culpas merecia». ${ }^{80}$ No obstante, los inquisidores no tomaron a pie juntillas las declaraciones del reo y dudaron acerca de la ingerencia del demonio en todos los actos declarados y entendieron, según su propia sentencia «que todos aquellos fingimientos de locura y revocaciones que avia hecho procedieron mas de la flaqueza de animo y del cortisimo temor que siempre tuvo». ${ }^{81}$ En ese caso, aunque abjuró de vehementi, Coronado tuvo la oportunidad de reconciliarse con toda la comunidad de cristianos. Muy distinta fue la suerte de Fray Francisco de la Cruz quien fue relajado, según los inquisidores, por «haber sido hereje pertinaz, heresiarca, dogmatizador y enseñador de nueva secta y errores y haber hecho y cometido todos los delitos de que fue acusado y otros muy muchos que ha confesado». ${ }^{82}$ Según el reo, los actos contra natura cometidos no los tenía por pecado, ya que «conoce que todas ellas an sido estando turbado de la razon y tan ciego de la pasion que podía justamente dubdar si avia tanta libertad en el juizio que fuese pecado mortal». ${ }^{83} \mathrm{No}$ obstante, en este caso al igual que en el de Coronado, los inquisidores no se convencieron de que aquello pudiera hacerse sin la voluntad del acusado, ya que «las cosas que dize y afirma son tan conformes a lo que la carne pide que es la mas apa-

\footnotetext{
77 AHN, Inquisición, Libro 1027, f. 232v.

${ }^{78}$ Heinrich Kramer y Jacob SPRENGER, Malleus Maleficarum... 93.

79 AHN, Inquisición, Libro 1028, f. 203v.

80 AHN, Inquisición, Libro 1028, f. 203v.

${ }^{81}$ AHN, Inquisición, Libro 1028, f. 205v.

82 AHN, Inquisición, Legajo 1650, f. 1697

${ }^{83}$ AHN, Inquisición, Libro 1032, f. 55v.
} 
rejada que se ynventado para traer a su dañada secta a todos generos de gente». 84 Con todo, uno de los calificadores, Juan del Campo, provincial franciscano, planteó sus dudas acerca de que aquellas declaraciones, por su inverosimilitud, pudieran proceder de un hombre en su sano juicio. Sin embargo, un análisis menos presuroso lo concienció de que se trataba de un artificio para propagar su secta y sus herejías y, junto al resto de los calificadores, concluía que «le parece que no esta loco sino en su juizio como antes lo estava y que no cree que aquel poco espacio estubo loco sino que fingio la locura como mañoso astuto y sagas que a de ser» .85

Como puede observarse, la inquisición peruana actúo de diversas maneras respecto a la naturaleza herética de la sodomía. Si bien por un lado la asimiló como una práctica sospechosa de herejía, en la medida en que, tanto por ignorancia como por pertinacia, su simple ejecución implicaba un error de fe, por otro lado, se preocupó por arrancar una proposición verbal acerca del delito que, indiscutiblemente, acreditara la presencia de herejía. En lo que respecta al contenido demonológico de la sodomía, los inquisidores también demostraron una actitud ambigua, ya que mientras en algunos casos compartieron junto a los reos la creencia de que este tipo de comportamiento sexual sólo podía ser persuadido, inducido e, incluso, perpetrado materialmente por el demonio, en otros casos, consideraron que ese tipo de manifestaciones sólo constituían desatinos o artilugios de los reos para disipar su responsabilidad y, de este modo, evadir las penas correspondientes.

Uno de los factores que permiten entender las diferentes respuestas de los magistrados frente a la sodomía está vinculado, justamente, con el rol determinante que tuvieron los jueces a la hora de administrar justicia. Después de todo, eran ellos quienes tenían la responsabilidad de interpretar los ordenamientos jurídicos, discernir su pertinencia y emplearlos en circunstancias concretas. Como señala Carlos Garriga, la cultura jurídica moderna fue más de una justicia de jueces que de leyes ${ }^{86}$ No obstante, aun cuando los magistrados ocuparan un lugar destacado en la interpretación del acto sodomítico y, por lo tanto, determinaran casuísticamente la existencia o no de herejía, las formulaciones que la patrística, los teólogos y los demonólogos elaboraron a lo largo de los siglos en torno a la sodomía jugó un rol central en el proceso de herejización del fenómeno. En ese sentido, no sólo nutrieron la practica inquisitorial sino que aportaron las condiciones teológicas necesarias para hacer inteligible, tanto judicial como socialmente, el contenido herético de la sodomía.

\footnotetext{
${ }^{84}$ AHN, Inquisición, Libro 1032, f. 67v.

85 AHN, Inquisición, Libro 1032, f. 68. Esta actitud de escepticismo de algunos inquisidores también puede observarse en el caso de la brujería. Algunos magistrados consideraban que el sabbat no era más que una simple ilusión y el hecho de que sus supuestos asistentes confesaran su existencia no implicaba que dicha existencia fuera tal. Henry Kamen, Notas sobre brujería... 229-231

${ }^{86}$ Carlos GarRIGA, «Sobre el gobierno de la justicia en Indias (siglos XVI-XVII), Revista de Historia del Derecho, 34 (2006) 85.

Hispania Sacra, LXII

126, julio-diciembre 2010, 539-562, ISSN: 0018-215-X
} 